\title{
STATIC TREMOR IN ANXIETY STATES
}

\author{
BY
}

\author{
JAMES D. P. GRAHAM, Capt. R.A.M.C.
}

(Received 5Th September, 1945)

\begin{abstract}
AcCording to Bucy (1944) " tremor as a clinical manifestation is divisible into two main groups which have no etiological connotations. They are tremor at rest, and intention tremor. Static tremor is another less common manifestation of intention tremor. Static tremor is present when the part is being voluntarily held still against the force of gravity-as when the arm is held outstretched". It may be defined as an irregular involuntary movement of small excursion and rapid rate, resulting from contraction of the opposing skeletal muscles in use to keep the part in its static position. This loose definition serves to distinguish it from voluntary movement, shivering, athetosis, choreiform movement and jactitation and convulsions.
\end{abstract}

Sollenberger (1937) concluded that " tremor is an inevitable phenomenon of postural contraction inherent in the simplest reflex arc and independent of the higher centres for its origin." In that case it seems to be a peripheral phenomenon related to the mode of action of the stretch reflex in protagonist and antagonist muscle groups, and is produced by the proprioceptive reflexes which maintain posture. Nevertheless Sollenberger realized that static tremor could be modified by the activity of the higher centres.

Tremor varies in different subjects and from time to time in any one subject, being accentuated by hunger, fatigue, and senility. Marked tremor in young or middle-aged patients may be due to toxicity (alcoholism, thyrotoxicosis), central nervous disease ("cerebellar tremor ") or anxiety. Harris (1934) gives a clinical classification of tremors; under the heading of "psychotic tremors" are included emotion, hysteria, neurasthenia, fright, shellshock, tics and habit spasms. The intention tremors accompanying such pathological states are an exaggeration of an underlying physiological mechanism. Lazarus and Bell (1943) showed that the rate and amplitude of static tremor in cases of hyperthyroidism was significantly greater than that of normal controls, but the difference was a matter of degree rather than of fundamental quality.

It is a universal clinical practice to observe flutter of the closed eyelids and tremor of the outstretched fingers; if this is coarse enough to be seen easily it is considered to be abnormal, but a fine " invisible" tremor is always capable of being recorded by magnifying the excursion of the part observed.
Wolfenden and Williams (1888) appear to have been the first in this country to make systematic records of tremors. They differentiated between static tremor in Grave's disease with a frequency of 11 per second, and the "tremor at rest " of Parkinsonism. Eshner (1897) studied physiological intention tremor, and considered that it was characterized by irregularity and that the frequency of movement bore an inverse relation to its extent. Bousfield (1932) and Lazarus and Bell (1943) contradict this so-called " Law of Tremor" which was propounded by Binet (1920) and supported by Tuttle and Voltmer (1939).

Closer analysis of the nature and cause of static tremor is difficult. A lead was given by Schafer (1886) with his analysis of voluntary movement in human muscle, and although Hill (1921) placed the number of impulses at 50 per second, the idea that intention tremor was related to the number of fused elements in the muscle tetanus was revived by Travis and Hunter (1927). Their records of action currents from muscles in contraction showed a modulated wave form. The electromyogram was made up of an audible frequency of 300-600 per second and an inaudible frequency of 10-13 per second. The relation between the latter and tremor in the muscles was close. This work is supported by Athanasiu (1923). The work of Adrian and Bronk (1929) on the cat was extended by Hoëfer and Putnam (1939), who studied action potentials in the muscle of man and found that for gentle contraction the frequencies of discharge of the individual motor unit ranged between 6 to 60 per second and that muscular contraction during the maintenance of " postural tone" might be sustained without fatigue for long periods. The site of origin of the impulses giving rise to intention tremor was determined by two lines of approach. Jasper and Andrews (1938) recorded tremor coincidentally with electroencephalogram records and concluded that the tremor originated in cortical impulses. The frequency of normal tremor was found to correspond closely with the frequency of potential rhythms from regions of the cortex anterior to the central fissure. This was denied by Travis and Hunter (1931). Fulton, Liddell, and Rioch (1932), and Aring and Fulton (1936) showed that the origin of cerebellar tremor in the cat lies in the excitable cortex of the cerebrum, while Putnam (1942) removed the 
intention tremor in man by section of the pyramidal tract in the cervical cord. Bucy (1944) stated that:

"Intention tremor and tremor at rest are produced by impulses passing from the precentral motor cortex to the anterior horn cells via the pyramidal tract. Intention tremor develops when a circular controlling pathway which passes from the precentral motor cortex to the pons, the cerebellar cortex, the dentate nucleus, through the red nucleus to the contralateral nucleus of the thalamus and thence back to the precentral motor cortex, is destroyed in the dentate nucleus, the dentato-rubrothalamic fiber bundle, or in the thalamus."

Tremor is a common but by no means constant feature of the anxiety state, Sutherland (1941) observing it in 66 per cent. of cases. According to Morgan (1943) there is a close relationship in humans between the prefrontal areas of the cortex and neurotic symptoms. Freeman and Watts (1939) have removed the emotional tensions of cases with severe anxiety by the operation of prefrontal leucotomy. It may be that anxiety state and one of its signs, exaggerated static tremor, are related to abnormal activity of the prefrontal cortex and the adjacent pre-motor area.

\section{Method}

The present report describes the findings in 100 unselected cases of anxiety state seen at a Military Hospital, from whom tremor of the R. index was recorded by the apparatus used by Lazarus and Bell (1943). This records optically the magnified movements of the finger. The finger is supported at the metacarpophalangeal joint; the hand and arm rest on a splint; a thimble bearing a fine wire covers the end of the index which can move freely. The pattern is recorded by focusing the shadow of the wire on to a camera. Posture was maintained by directing the tip of the wire at a target. Distances were arranged to give a magnification of eight times. Records were taken without the patients' knowledge for not less than 4 seconds, and the mean rate of tremor calculated from the waves over this period. It is difficult to strike a mean figure for the amplitude of a tremor record. This was attempted by direct measurement. Complete reversal of direction in the record counts as one wave; alterations in base-line are ignored. Super-imposed waves are counted if they fit these criteria.

The majority of the cases had been diagnosed by a Psychiatrist; the rest were undoubtedly suffering from abnormal anxiety. This was associated with emotional instability, conflict between duty and inclination, financial and domestic worries, past battle trauma or fear of future battle experiences and the syndrome of irritability, "jumpiness" headaches and somatic dysfunction, for which no organic basis could be found despite searching inquiry.

\section{Results and Discussion}

A control group of 52 persons between the ages of 18 years and 52 years of age (mean 25 years) was examined. Of these 25 per cent. showed obvious tremor, the mean tremor rate for the whole group being 13.4 per sec. with an amplitude of $0.213 \mathrm{~mm}$. This agrees well with Young (1933) who recorded a rate of $12 / \mathrm{sec}$. in normal subjects. The relationship between rate and amplitude of tremor was not constant. A tremor of small amplitude may be frequent or slow but a tremor of large amplitude is seldom fast (over $20 / \mathrm{sec}$.); a fast tremor is usually of small amplitude. These statements apply to tremors recorded from normal controls who were fit (army medical category A1) and not affected by fatigue, hunger, or emotional upset. The clinical belief that slow tremors are "coarse" (of greater amplitude) and fast tremors are "fine" (of lesser amplitude) holds true as a clinical observation, because the slow tremor of fine amplitude is invisible and the fast tremor of large amplitude is rare, leaving the two clinical grades of "fine" and " coarse" to be seen. Accurate analysis by instrumental recording shows that there is no constant relation between age, sex, rate or amplitude in static tremor; like the pulse in auricular fibrillation it is irregularly irregular. It varies in rate from moment to moment and in amplitude from wave to wave, but even this rule of variability has its exceptions. Fig. 1 illustrates typical static tremor as recorded from normal controls.

Analysis of the 100 non-selected cases of anxiety state (age 18-52 years) by symptomatology gives

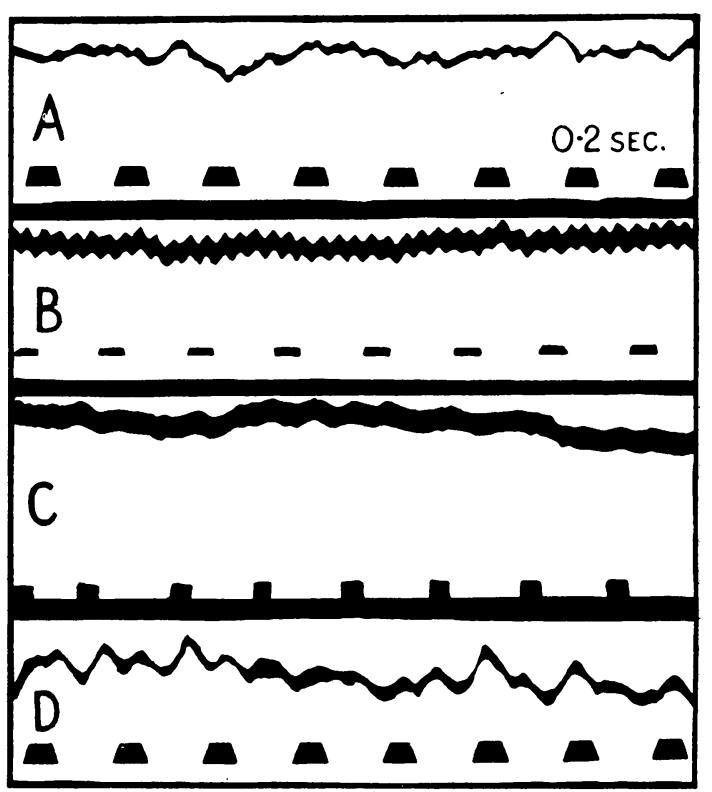

FIG. 1.-Normal static tremor $\times 8$. Irregularly irregular. Time in $0 \cdot 2$ secs.

A. Rate 13 per sec., amplitude $0.22 \mathrm{~mm}$; average trace.

B. Clinically noticeable " fine" tremor. Rate 24 per sec., amp. 0.125 mm.

C. Clinically invisible tremor of same amp. as B, rate 8 per sec.

D. "Coarse" tremor, rate as in C, amp. $0.62 \mathrm{~mm}$.

The observation of tremors $\mathrm{B}$ and $\mathrm{D}$ and the missing of $C$ gives rise to the clinical conception of "fine " (rapid rate and small amplitude) and " coarse" (slow rate and large amp.) tremors.

the Ifollowing results. The main symptom was indigestion in 26 per cent., headaches 20 per cent., respiratory 10 per cent., cardiac 7 per cent., myalgia 7 per cent., and miscellaneous 24 per cent. Tremor was obvious on clinical examination in 71 per cent. of these cases, which agrees well with the findings of Sutherland (1941). 
The tremors had a mean rate of 14.33 cycles per $\mathrm{sec}$. and a mean amplitude of $0.42 \mathrm{~mm}$. The range of vibration rates $(5-27 / \mathrm{sec}$.) was similar to that found in the controls $(5-24 / \mathrm{sec}$.) but the range of amplitude was wider $(0.062-2.625 \mathrm{~mm}$., as compared with 0.062-0.625 mm.). The significant difference lay in the greater amplitude in the anxiety group, which thus has a "coarser" tremor than normal. This difference is particularly marked in female cases.

TABle I.-AMPLITUDE OF ANXIETY TREMOR SIGNIFICANTLY GREATER THAN AMPLITUDE OF NORMAL TREMOR; NO DIFFERENCE IN TREMOR RATES

$$
\begin{array}{ll}
\text { TR }=\text { Tremor Rate } & \text { TA }=\text { Tremor Amplitude } \\
\mathbf{C}=\text { Controls } & \mathrm{A}=\text { Anxiety State }
\end{array}
$$

\begin{tabular}{|c|c|c|c|c|}
\hline & Mean & Range & $\sigma$ & $\mathbf{N}$ \\
\hline \multirow{4}{*}{\multicolumn{2}{|c|}{$\begin{array}{ccc}\text { TR(C) } \ldots & 13.39 \\
\text { TR(A) } \ldots & 14.33 \\
& \text { Difference } \\
& \text { S.E. of D. } \\
\text { TA(C) } \ldots & 0.213 \mathrm{~mm} . \\
\text { TA(A) } \ldots & 0.4245 \mathrm{~mm} . \\
& \\
& \text { Difference } \\
& \text { S.E. of D. }\end{array}$}} & \multirow{4}{*}{$\begin{array}{l}5-24 / \mathrm{sec} . \\
5-27 / \mathrm{sec} . \\
0.94 \\
\pm 0.80 \\
0.062 \\
0.625 \mathrm{~mm} . \\
0.062 \\
0.625 \mathrm{~mm} . \\
0.212 \\
=0.046\end{array}$} & $\begin{aligned} \pm & 4 \cdot 34 \\
\pm & 5 \cdot 01 \\
& \quad \text { Not sig }\end{aligned}$ & $\begin{array}{r}50 \\
100 \\
\text { icant }\end{array}$ \\
\hline & & & $\doteqdot 0.144$ & 50 \\
\hline & & & \pm 0.412 & 100 \\
\hline & & & \multicolumn{2}{|c|}{$\begin{array}{c}\mathrm{D}=4.6 \times \mathrm{S} . \mathrm{E} . \\
\text { Significant }\end{array}$} \\
\hline
\end{tabular}

It is not possible to assess objectively the clinical severity of cases in order to correlate the amplitude of tremor with the degree of abnormality, but it has been observed that a severe degree of anxiety may be present without marked tremor.

Fig. 2 illustrates the tremors found in typical cases of anxiety. The pattern is completely irregular and rate and amplitude are not proportionally related. There is no direct correlation with age or sex.

If static tremor is the manifestation of a physiological proprioceptive mechanism and the difference between static tremor in " normal " and " anxious" subjects is one of degree of amplitude of this tremor rather than of rate of tremor (see Fig. 3), the proprioceptive reflex motor response in pathological anxiety is increased. There is no tremor apparent in the resting muscle of normal or anxious subjects (e.g. during sleep) nor in the muscle paralysed by nerve section or anterior horn cell destruction (poliomyelitis). Static tremor is dependent upon an intact reflex arc. It is absent in hemiplegics because it is also dependent on active contraction of anti-gravity muscles and the muscle of the hemiplegic is paralysed though the reflex arc may be intact (cf. Travis, 1929). Pathological anxiety has been relieved by prefrontal leucotomy. Since coarseness of static tremor is a manifestation of anxiety it would appear that the tremor-causing reflexes are affected by the state of the higher centres to which they must be linked. The normal kinæsthetic stimulus is responded to by an over active motor response. It is tentatively suggested that this may be due to a spread from the prefrontal cortex to the premotor cortex, as indicated by Bucy (1942),

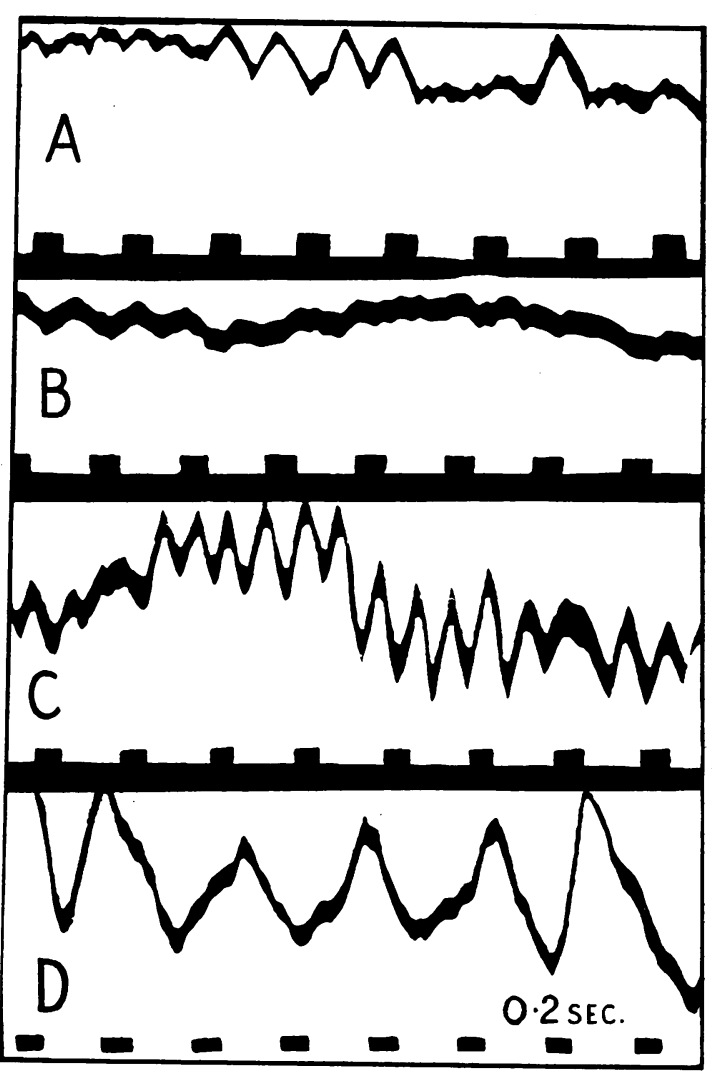

FIG. 2.-Tremor pattern in anxiety state $\times 8$. Time in $0.2 \mathrm{sec}$. Completely irregular.

A. Average record. Rate 13 per sec., amp. $0.4 \mathrm{~mm}$.

B. Rate $8 \cdot 5$ per sec., amp. $0 \cdot 125 \mathrm{~mm}$. Contrast with

C. Rate 8.5 per sec., amp. $1.75 \mathrm{~mm}$. There is no constant relationship between rate and amplitude.

D. An unusually " coarse" tremor, rate 5 per sec., amp. $2 \cdot 0 \mathrm{~mm}$.

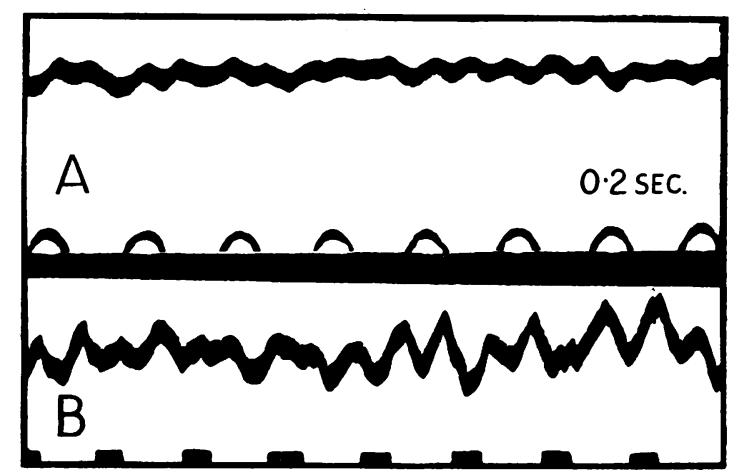

FIG. 3.-Difference in amplitude is the significant difference between " normal" and " anxiety" static tremors.

A. Normal. Rate 10 per sec., amp. $0.25 \mathrm{~mm}$.

B. Anxiety. Rate 10 per sec., amp. 0.60 mm.

who postulated that tremor was due to the inactivation of specific "suppressor" areas in the cortex which normally inhibit other specific pre-central areas. "Release" of these areas results in hyperactivity down parapyramidal and pyramidal tracts so that various abnormal movements result.

The nature of the "parapyramidal impulses" is 
not clear, but their effect as seen in tremor in anxiety would appear to be a facilitation of the motor neurone effecting the local kinæsthetic reflexes so that larger groups respond to a given impulse and grosser movements result, perhaps by a process of central summation. If the stream of " extra pyramidal impulses" increase the central excitatory state in the anterior horn cells of the cord the normal myotatic reflex impulses from the posturing muscle will enter a subliminal fringe or " irritative focus." Summation of the two ineffective impulses causes a liminal state of c.e.s. and the discharge of an increased number of motoneurones, hence the coarser tremor of anxiety; speeds of tremor will be unaffected. This theory accords with the results found in the present investigation.

\section{Summary}

Tremor of the R. index was recorded from 52 normal subjects and 100 unselected cases of anxiety state.

The normal tremor showed a rate of $13 / \mathrm{sec}$. and an amplitude of $0.2 \mathrm{~mm}$. It was noticeable clinically in 25 per cent. of subjects.

Anxiety gave rise to an increase in amplitude of tremor. Anxiety tremor showed a rate of $14 / \mathrm{sec}$. and $0.4 \mathrm{~mm}$. amplitude. Neither tremor showed any fixed relationship between rate and amplitude; they were completely irregular. Anxiety tremor is considered to be a development of physiological static tremor as a result of augmentation of the motor side of a proprioceptive reflex of the " antigravity" muscles, due to facilitation of the motor neurones by central influences.

It is desired to express thanks to Dr. Bell, of the Institute of Physiology, Glasgow, for the use of apparatus and for advice and criticism; and to Colonel E. B. Marsh, M.C., M.R.C.P., Officer Commanding, a Military Hospital, for facilities in carrying out the practical investigations.

\section{REFERENCES}

Adrian, E. D., and Bronk, D. W. (1929). J. Physiol., 67 119

Aring, C. D., and Fulton, J. F. (1936). Arch. Neurol. Psychiat. (Chicago), 35, 439.

Athanasiu, J. (1923). J. Phys. Path. gen., 21, 1.

Binet, L. (1920). Lancet, 1, 265.

Bousfield, W. A. (1932), J. exp. Psychol., 15, 104.

Bucy, P. C. (1944). The Precentral Motor Cortex. Univ. Illinois Press. Urbana, Ill. (1942). J. Neuropath. exp. Neurol., 1, 224.

Eshner, A. A. (1897). J. exp. Med., 2, 301.

Freeman, W. A., Watts, J. W. (1939). Yale J. Biol. Med., 11, 527.

Fulton, J. F., Liddell, E. G. T., and Rioch, D. M. (1932). Arch. Neurol. Psychiat. (Chicago), 28, 542.

Harris, W. (1934). Lancet, 2, 1145.

Hill, A. V. (1921). J. Physiol., 55, P. xiv.

Hoëfer, P. F. A., and Putnam, T. J. (1939). Arch. Neurol. Psychiat. (Chicago), 42, 201.

Jasper, H. H., and Andrews, H. L. (1938). J. Neurophysiol., 1, 87.

Lazarus, S., and Bell, G. H. (1943). Glasgow med. J., 140, 77.

Morgan, C. T. (1943). Physiological Psychology. Megraw Hill, New York, p. 563.

Putnam, T. J. (1942). Assoc. Res. nerv. ment. Dis., Procs., 21, 666.

Schäfer, E. A. (1886). J. Physiol., 7, 111.

Sollenberger, R. T. (1937). J. exp. Psychol., 21, 579.

Sutherland, J. D. (1941). Brit. med. J., 2, 365.

Travis, L. E. (1929). J. exp. Psychol., 12, 515 and Hunter, T. A. (1927). Amer. J. Physiol., 81, 355.

- (1931). J. gen. Psychol., 5, 255.

Tuttle, W. W., and Voltmer, E. J. (1939). Arbeits. Physiol., 10, 530.

Wolfenden, R. N., and Williams, D. (1888). Brit. med. $J ., 1,1049$.

Young, I. C. (1933). J. exp. Psychol., 16, 644. 